\title{
Diffuse Panbronchiolitis is not Restricted to East Asia-a Mini Literature Review
}

\author{
Ram Kumar Mishra \\ Epidemiology and HEOR Team, ODC 3, Tata Consultancy Services, Thane (W), Maharashtra, India
}

DOI: https://doi.org/10.17925/USRPD.2017.12.02.30

\section{Keywords}

Diffuse panbronchiolitis, erythromycin, interstitial lung disease, macrolide therapy, rare disease

Disclosure: Ram Kumar Mishra has nothing to declare in relation to this article. Opinions expressed in this article are the author's own findings and do not in any manner reflect or represent the view of the organization to which he is affiliated.

Compliance with Ethics: This study involves a review of the literature and did not involve any studies with human or animal subjects performed by any of the authors.

Authorship: All named authors meet the International Committee of Medical Journal Editors (ICMJE) criteria for authorship of this manuscript, take responsibility for the integrity of the work as a whole, and have given final approval to the version to be published.

open Access: This article is published under the Creative Commons Attribution Noncommercial License, which permits any noncommercial use, distribution, adaptation, and reproduction provided the original author(s) and source are given appropriate credit.

Received: October 11, 2017

Accepted: December 7, 2017

Citation: US Respiratory \& Pulmonary Diseases, 2017;2(1):30-2

Corresponding Author: Ram Kumar Mishra, Epidemiology and HEOR Team, ODC 3, Tata Consultancy Services (TCS), 5th Floor, Lexington, Hiranandani Estate, Thane (W), Maharashtra, India 400 607. E: mishra.ram@tcs.com

Support: No funding was received in

the publication of this article.
Diffuse panbronchiolitis (DPB) is a rare inflammatory lung disease. It was first identified in 1969 and is well recognized in East Asian countries such as Japan, China, Taiwan, and Korea. ' 'Diffuse' and 'pan' words in the name indicate 'presence of lesions through both the lungs,' and inflammation in all layers of bronchioles.

At the time of its discovery, DPB had poor prognosis because of recurrent respiratory infections leading to respiratory failure. In the years following the initial description of DPB in Japan, cases were also identified in other parts of Asia including China and Taiwan, thus giving it recognition as a distinct clinical entity. Over the years, sporadic DPB cases have been reported worldwide in countries other than Japan, China, Taiwan, and Korea (hereafter referred to as rest of the world [ROW]). This stimulated us to undertake a comprehensive search for available case studies on DPB. The aim of this study was to present the current clinical evidence captured as DPB case studies across the globe excluding East Asian countries.

A total of 657 studies regarding DPB were retrieved from PubMed in a systematic manner (Figure 1). Forty-eight case studies published in ROW and indexed in PubMed were included in the final review.

As indicated in Figure 2, the maximum number of DPB cases among ROW countries were published from the US $(18.75 \%, n=9){ }^{2-10}$ jointly followed by Australia, ${ }^{11-15}$ France, ${ }^{16-20}$ and Italy ${ }^{21-25}$ (each $10.41 \%$, $\mathrm{n}=5$ ), respectively. There were three DPB cases published each from India ${ }^{26-28}$ and Turkey, ${ }^{29-31}$ and two case studies each from Belgium, ${ }^{32,33}$ Brazil, ${ }^{34,35}$ Germany, ${ }^{3,37}$ and Thailand. ${ }^{38,39}$ One case report each was reported from Canada ${ }^{40}$ Ireland ${ }^{41}$ Malaysia ${ }^{42}$ Netherlands, ${ }^{43}$ New Zealand, ${ }^{44}$ Norway ${ }_{15}^{45}$ Portugal, ${ }^{46}$ Singapore, ${ }^{47}$ Spain, ${ }^{48}$ and the UK. ${ }^{4}$

It is interesting to note that a majority $(50 \%, n=24)$ of DPB studies were from four developed countries. Twelve of 48 studies (25\%) reported DPB in patients of East Asian origin (either they immigrated to other countries or were born to East Asian parents). Patients were reported either by race (Caucasian, ${ }^{13,40}$ Hispanic, African-American ${ }^{4,9}$ ) or ethnicity (American citizens, White patients, Oriental [Asian] immigrant, ${ }^{3}$ Cambodian man, White man in Turkey, ${ }^{29}$ Turkish girl, ${ }^{30}$ Italian man, ${ }^{21,22}$ man of Indian ethnicity, ${ }^{44}$ Scandinavian patient, ${ }^{45}$ non-Asian Brazilian citizen, ${ }^{34}$ and Caucasian man of Canadian origin ${ }^{40}$ ). None of these patients with DPB had ever travelled outside of their country until DPB was diagnosed, except for one Hispanic patient with an extensive travel history to Far Eastern countries including Japan. ${ }^{5}$ Though most of the cases reported adult patients with DPB, two studies presented DPB cases in children. One case presented a 10-year-old child of Korean birth, ${ }^{10}$ and the other reported a 12-year-old Turkish girl with DPB. One study reported DPB recurrence in an African-American man after bilateral sequential lung transplantation. ${ }^{4}$ 
Figure 1: Study flow diagram

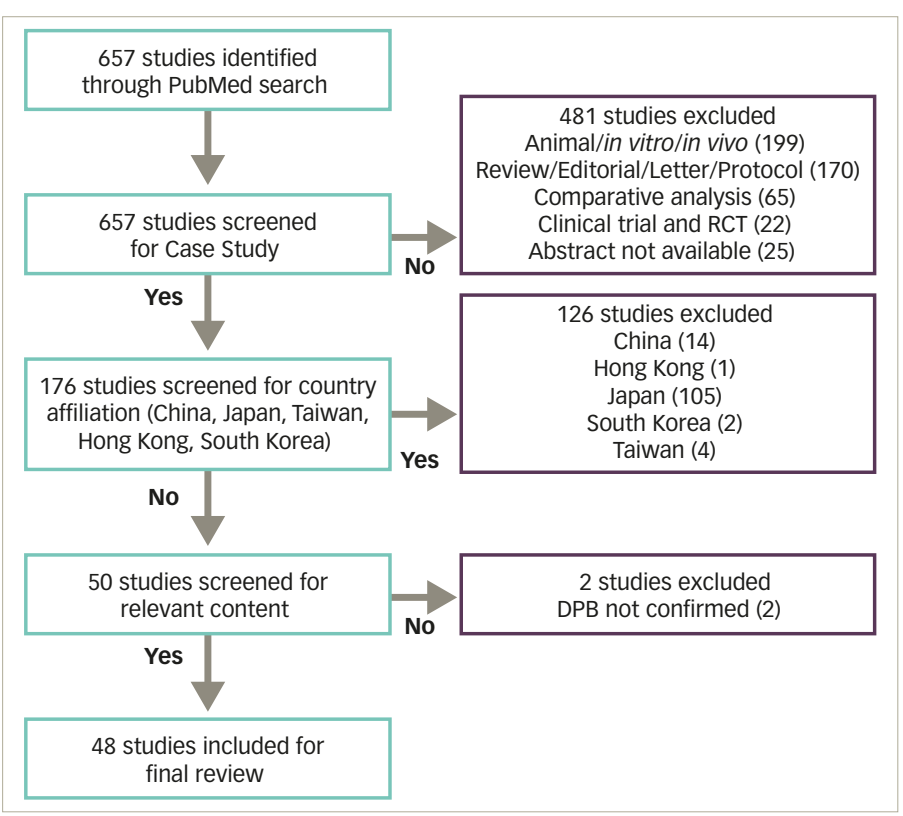

The PubMed Search was carried out on April 30, 2017. DPB = diffuse panbronchiolitis; $R C T=$ randomized controlled trial

In the past, some publications had attributed lack of clinical awareness and diagnostic familiarity in ROW countries with under-diagnosis and failure of treatment of DPB. ${ }^{8}$ It was demonstrated that East Asians have more chance to possess the human leukocyte antigen (HLA) serotype-Bw54, which was demonstrated to be associated with DPB..$^{50}$ In the present study, HLA-Bw54 serotype testing was carried out in 8 cases (16.7\%), whereas high-resolution computed tomography (HRCT) was reported in 21 cases (43.8\%). Other methods such as chest radiography (X-ray) or computed tomography (CT) were popularly utilized in different studies for clinical decision-making. Apart from these, 25 of 48 studies (52.1\%) relied on histopathological investigations (surgical, bronchoscopy, open lung or trans-bronchial biopsy etc.) to confirm the diagnosis of DPB. The fact that there were a total of 13 DPB cases from six countries nearby to East Asia (Australia, 5 studies; New Zealand, 1; India, 3; Thailand, 2; Singapore, 1; and Malaysia, 1 study) raises concerns.

Since DPB treatment and prognosis are different from other obstructive pulmonary diseases, the chances of misdiagnosis are high. Early diagnosis, identification and early initiation of low-dose macrolide therapy can lead to improved survival. Patients with DPB described from ROW countries may also increase if this disease is taken into consideration in differential diagnosis of sinopulmonary diseases. Differential diagnoses of DPB include chronic bronchitis, bronchiectasis, primary ciliary dyskinesia, cystic fibrosis, hypogammaglobulinaemia, and bronchiolitis..$^{51}$ Diagnostic criteria proposed in 1998 by a working group of the Ministry of Health and Welfare of Japan ${ }^{52}$ include: (a) persistent cough, sputum, and exertional dyspnea; (b) history of chronic paranasal sinusitis; (c) bilateral diffuse small nodular shadows on a plain chest X-ray (CXR) film or centrilobular micronodules on chest computed tomography (CT) images; (d) coarse crackles; (e) ratio of forced expiratory volume (FEV1) and forced vital capacity $(\mathrm{FVC})<70 \%$, arterial oxygen tension $(\mathrm{PaO} 2)<80 \mathrm{mmHg}$; and
Figure 2: Diffuse panbronchiolitis case reports from several countries, excluding East Asian countries

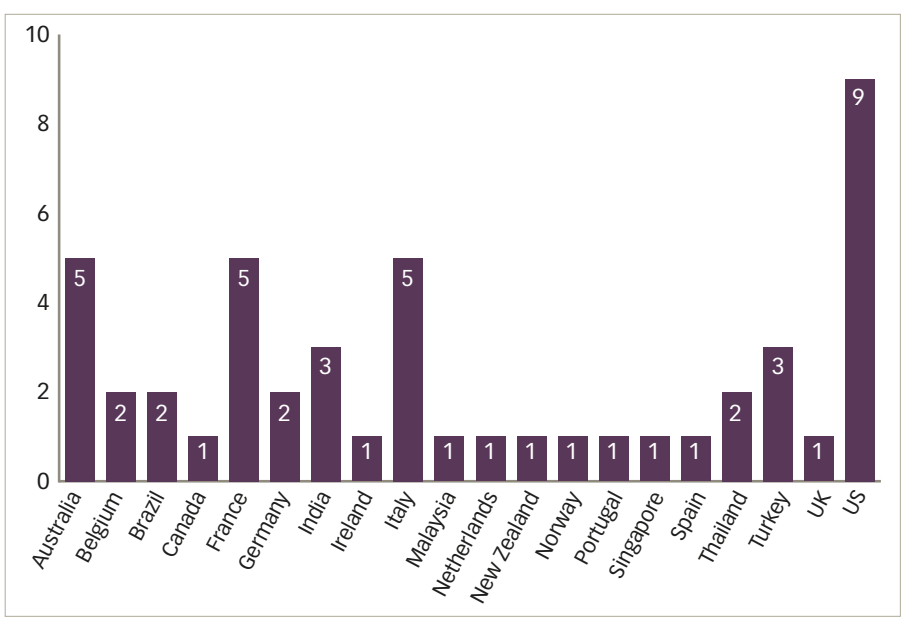

( $f$ ) titer of cold hemagglutinin $\geq 64$. Established DPB cases should fulfill criteria $a, b$, and $c$, along with at least two of criteria $d, e$, and $f$.

Multiple factors might be involved in the increased number of DPB cases from the ROW. Though nothing is known about the etiology of DPB, an increasing number of articles mentioning the importance of correct DPB diagnosis cannot be ignored. It is evident that lung biopsy remained the most reliable technique for confirmatory diagnosis of DPB (>50\% cases) in ROW countries where the disease is rare and clinicians are not familiar with it. Additionally, HRCT is now preferred over CT scan and chest radiographs these days as it provides non-overlapping patterns which are highly suggestive of the diagnosis, when compared with CT. Also, being a non-invasive method to assess treatment response without the need for repeated histological evaluation, HRCT might help to retain patients with DPB until the end of treatment. Since macrolide levels in the airways of patients with DBP are well below the minimal level to exhibit antibacterial effects, anti-inflammatory and immuno-modulatory effects can be attributed to a beneficial effect of low-dose, long-term macrolide therapy. ${ }^{53}$

Established diagnostic criteria and treatment guidelines are well known in East Asian countries where the disease incidence is higher. But, as is evident from case studies in this article, the emerging global footprint of this disease raises concerns. There is a need to make clinicians aware and familiar with DPB, and to recognize it as global sinobronchial disease by discussing its diagnostic features to help pulmonologists able to recognize and treat this disease without delay. The observation that the majority of DPB case studies were identified in developed countries (US, Italy, France, and Australia [Figure2]) can be attributed to increasing awareness amongst pulmonologists.

To conclude, the effects of DPB under-reporting due to lack of awareness and recognition leading to misdiagnosis and delayed (or lack of) treatment, cannot be ignored. Though sporadic cases from other geographical regions have been reported in past, the chances of DPB being misdiagnosed cannot be ignored. Timely diagnosis and intervention initiation can be life saving for many potential patients who might have been misdiagnosed. $\square$ 
1. Homma H, Yamanaka A, Tanimoto S, et al., Diffuse panbronchiolitis: a disease of the transitional zone of the lung Chest, 1983;83:63-9.

2. Desai SJ, Gephardt GN, Stoller JK, Diffuse panbronchiolitis preceding ulcerative colitis, Chest, 1989;95:1342-4.

3. Randhawa $\mathrm{P}$, Hoagland $\mathrm{MH}$, Yousem SA, Diffuse panbronchiolitis in North America. Report of three cases and review of the literature, Am J Surg Pathol, 1991;15:43-7.

4. Baz MA, Kussin PS, Van Trigt P, et al., Recurrence of diffuse panbronchiolitis after lung transplantation, Am J Respir Crit Care Med, 1995:151:895-8.

5. Homer RJ, Khoo L, Smith GJ, Diffuse panbronchiolitis in a Hispanic man with travel history to Japan, Chest, 1995;107:1176-8

6. Fitzgerald JE, King TE Jr, Lynch DA, et al., Diffuse panbronchiolitis in the United States, Am J Respir Crit Care Med, 1996;154:497-503.

7. Fisher MS Jr, Rush WL, Rosado-de-Christenson ML, et al., Diffuse panbronchiolitis: histologic diagnosis in unsuspected cases involving North American residents of Asian descent, Arch Pathol Lab Med, 1998;122:156-60.

8. Krishnan P, Thachil R, Gillego V, Diffuse panbronchiolitis: treatable sinobronchial disease in need of recognition in the United States, Chest, 2002;121:659-61.

9. Boroumand N, Cooke R, Prys-Picard C, et al., Idiopathic bronchiolitis with features of diffuse panbronchiolitis in an African-American patient with hepatitis C virus infection, Ann Diagn Pathol, 2010;14:443-6.

10. Weinberger $M$, Fischer $A$, Kao S, Diffuse panbronchiolitis in a 10-year-old boy, Pediatr Pulmonol, 2015;50:E32-4.

11. Ng P, Dwyer R, Despas P, Diffuse panbronchiolitis: case report and review of the literature, Australas Radiol, 1998;42:146-50.

12. Claxton S, Markos J, A case of diffuse panbronchiolitis, Aust N Z J Med, 2000;30:99-100

13. Anthony M, Singham S, Soans B, Tyler G, Diffuse panbronchiolitis: not just an Asian disease: Australian case series and review of the literature, Biomed Imaging Interv J, 2009;5:e19.

14. Brown J, Simpson G, Diffuse panbronchiolitis in an Australian aborigine, Respirol Case Rep, 2014;2:64-6.

15. Gibson J, King H, Singh M, Tran K, Diffuse panbronchiolitis in a Samoan man, Respirol Case Rep, 2017;5:e00217.

16. Tredaniel J, Zalcman G, Gerber F, et al., Diffuse panbronchiolitis: efficacy of low-dose erythromycin, Respir Med, 1993;87:229-30

17. Trédaniel J, Cazals-Hatem D, Zalcman G, et al., Diffuse panbronchiolitis: efficacy of low-dose erythromycin, Respir Med 1994;88:479-80.

18. Brugiere $\mathrm{O}$, Milleron $\mathrm{B}$, Antoine $\mathrm{M}$, et al., Diffuse panbronchiolitis in an Asian immigrant, Thorax, 1996;51:1065-7.

19. Courbot $A$, Chabot $F$, Jankowski R, et al., [Sinobronchial syndrome], Rev Mal Respir, 2001;18:193-6.
20. Tossier C, Pilette $C$, Guilleminault $L$, et al., Diffuse panbronchiolitis and IgA nephropathy, Am J Respir Crit Care Med, 2014:189:106-9.

21. Poletti V, Patelli $M$, Poletti $G$, et al., Diffuse panbronchiolitis observed in an Italian, Chest, 1990:98:515-6.

22. Poletti V, Patelli M, Poletti G, et al., Diffuse panbronchiolitis observed in an Italian male, Sarcoidosis, 1992;9:67-9.

23. Zompatori M, Poletti V, Diffuse panbronchiolitis. An Italian experience, Radiol Med, 1997;94:680-2.

24. Trisolini R, Cancellieri A, Paioli D, et al., Sarcoidosis in the setting of idiopathic chronic bronchiolitis with airway colonization from P. aeruginosa: treatment with low-dose macrolides, Intern Med 2008:47:537-42.

25. Ginori A, Barone A, Bennett D, et al., Diffuse panbronchiolitis in a patient with common variable immunodeficiency: a casual association or a pathogenetic correlation?, Diagn Pathol, 2014;9:12

26. Jadhav S, Joshi JM, Diffuse panbronchiolitis associated with malignant thymoma, Indian I Chest Dis Allied Sci, 2010;52:41-2.

27. Nath A, Aggarwal AN, Gupta R, Diffuse panbronchiolitis: report of a rare disease from India, Indian I Chest Dis Allied Sci, 2010;52:43-5.

28. Tirpude $S$, Karkhanis V, Joshi JM, A potentially misdiagnosed suppurative and obstructive airway disease, J Postgrad Med 2012;58:302-4

29. Gulhan M, Erturk A, Kurt B, et al., Diffuse panbronchiolitis observed in a white man in Turkey, Sarcoidosis Vasc Diffuse Lung Dis, 2000;17:292-6.

30. Aslan AT, Ozcelik U, Talim B, et al., Childhood diffuse panbronchiolitis: a case report, Pediatr Pulmonol, 2005:40:354-7.

31. Atici AG, Findik S, Sengul B, et al., Diffuse panbronchiolitis, a potentially misdiagnosed sinopulmonary syndrome, Ann Saud Med, 2005;25:501-4

32. De Smet K, De Maeseneer M, Ilsen B, De Mey J, Diffuse panbronchiolitis in a 67-year-old Chinese man, Emerg Radiol, 2011;18:169-71.

33. Hanon S, Verbanck S, Schuermans $D$, et al., Evidence of improved small airways function after azithromycin treatment in diffuse panbronchiolitis, Respiration, 2012:84:75-9.

34. Martinez JA, Guimarães SM, Ferreira RG, Pereira CA Diffuse panbronchiolitis in Latin America, Am J Med SCi, 2000;319:183-5

35. Souza R, Kairalla RA, Santos Ud Ude P, et al., Diffuse panbronchiolitis: an underdiagnosed disease? Study of 4 cases in Brazil, Rev Hosp Clin Fac Med Sao Paulo, 2002;57:167-74.

36. Schulte W, Szrepka A, Bauer PC, et al., [Diffuse panbronchiolitis. A rare differential diagnosis of chronic obstructive lung disease], Dtsch Med Wochenschr, 1999:124:584-8.

37. Breidert $M$, Janssen-Langenstein $R$, Hambrecht $S$, [A 63 year old Turkish woman with recurrent pneumonia], Internist (Berl), 2007:48:420-5

38. Chantarotorn S, Palwatwichai A, Vattanathum A, Tantamacharik D, Diffuse panbronchiolitis, the first case reports in Thailand, $J$ Med Assoc Thai, 1999;82:833-8

39. Palwatwichai A, Chaoprasong C, Vattanathum A, et al., Clinical, laboratory findings and microbiologic characterization of bronchiectasis in Thai patients, Respirology, 2002;7:63-6.

40. Sandrini A, Balter MS, Chapman KR, Diffuse panbronchiolitis in a Caucasian man in Canada, Can Respir J, 2003;10:449-51.

41. MCGrath EE, McLaughlin AM, Fitzgerald MX, Diffuse panbronchiolitis: East meets West, Eur Respir J, 2007:29:817-8.

42. Zainudin BM, Roslina AM, Fadilah SA, et al., A report of the first three cases of diffuse panbronchiolitis in Malaysia, Med J Malaysia, 1996;51:136-40.

43. Majoor CJ, Cox AL, Aliredjo RP, Dekhuijzen PN, [Diffuse panbronchiolitis in an Asian woman with severely obstructed pulmonary disease], Ned Tijdschr Geneeskd, 2006;150:1251-6.

44. Lum D, Wong C, Anderson G, Taylor G, Test and teach. Number Fifty-three. A rare lung disease in an Indian man. Diagnosis: Diffuse panbronchiolitis, Pathology, 2007:39:594-7.

45. Naalsund A, Foerster A, Aasebø U, et al., [An answer to an inquiry on diffuse panbronchiolitis. Now it has found its way here!], Lakartidningen, 1995;92:3119-21.

46. Carvalho L, Freitas S, [Vasculitis and diffuse panbronchiolitis-like in systemic lupus erythematosus--case report], Rev Port Pneumo 2007;13:267-74

47. Poh SC, Wang YT, Wang WY, Diffuse panbronchiolitis--a case report, Singapore Med J, 2001:42:271-4.

48. Urbano Aranda Y, García San José I, López Gabaldón E, Diffuse panbronchiolitis: a very rare disease in Western countries, Arch Bronconeumol, 2012;48:184-5.

49. Adams NP, Congelton J, Diffuse panbronchiolitis, Eur Respir J 2008:32:237-8.

50. Sugiyama Y, Kudoh $\mathrm{S}$, Maeda $\mathrm{H}$, et al., Analysis of HLA antigens in patients with diffuse panbronchiolitis, Am Rev Respir Dis, 1990;141:1459-62.

51. Poletti V Casoni G, Chilosi M, Zompatori M, Diffuse panbronchiolitis, Eur Respir J, 2006;28:862-71.

52. Izumi TA, Nation-wide survey of diffuse panbronchiolitis and the high incidence of diffuse panbronchiolitis seen in Japanese respiratory clinics, In: Grassi C, Rizzato G, Pozzi E (Eds) Sarcoidosis and other granulomatous disorders, New York, NY: Elsevier Science Publishers, 1988:753.

53. Jaffe A, Bush A, Anti-inflammatory effects of macrolides in lung disease, Pediatr Pulmonol, 2001:31:464-73. 